\title{
Women Psychologists within Academic Health Systems: Mentorship and Career Advancement
}

\author{
Cheryl A. King ${ }^{1,3}$ and Barbara Cubic ${ }^{2}$
}

\begin{abstract}
Women are underrepresented on the faculties and within the senior leadership ranks of academic health systems. Nevertheless, despite the continuing existence of career development challenges related to gender, it is possible for women to thrive professionally in these settings. Mentorship is extremely important, and it is argued that effective mentorship is facilitated by an understanding of both gender differences in social behaviors and the culture of academic health systems. Furthermore, a systems' level emphasis on faculty diversity and the career development of women faculty is recommended.
\end{abstract}

KEY WORDS: mentorship; under-representation of women; gender differences; academic health centers.

\section{INTRODUCTION}

Reliable estimates of the number of women employed as psychologists in academic health settings are difficult to ascertain. What is known is that women comprised $75 \%$ of the doctoral students and $44 \%$ of the faculty in 2002-2003 accredited doctoral programs (American Psychological Association [APA], 2004a). In contrast, data from Women in U.S. Academic Medicine Statistics (Association of American Medical Colleges [AAMC], 2003) showed that women in general have an uphill battle in medical settings and still remain an underrepresented group (Yedidia \& Bickel, 2001). With 126 U.S. medical schools reporting, $30 \%$ of faculty members are women and at least 18 schools have no women serving as department chairs. This under-representation of female faculty is even more disconcerting when contrasted with a recent report by the AAMC, which found that in 2004, women represented the majority of medical school applicants.

\footnotetext{
${ }_{1}^{1}$ Department of Psychiatry, University of Michigan Medical School, Ann Arbor, Michigan.

${ }^{2}$ Department of Psychiatry and Behavioral Sciences, Eastern Virginia Medical School, Norfolk, Virginia.

${ }^{3}$ Correspondence should be addressed to Cheryl A. King, Department of Psychiatry, University of Michigan Medical School, 1500 E. Medical Center Drive, Ann Arbor, Michigan 48109-0295.
}

Of equal or perhaps greater importance, women are less likely than men to be promoted to the levels of associate or full professor (Nonnemaker, 2000) and less likely to be appointed to search committees, which influence future faculty representation (AAMC, 2003). In a recent report of the AAMC Project Implementation Committee, Increasing Women's Leadership in Academic Medicine, it is noted that women comprise only $14 \%$ of tenured faculty and $12 \%$ of full professors, and that the average number of female department chairs in the United States is just 1.7 per medical school (Bickel et al., 2002). Based on these numbers the committee concluded the following.

\footnotetext{
...the progress achieved within academic medicine over the last 25 years is incomplete and inadequate. Few schools, hospitals, or professional societies have what might be considered a "critical mass" of women leaders, and the pool of women from which to recruit academic leaders remains small. Scientific and medical careers involve considerable personal and public investment, but the potential of most women is being wasted. (p. 1)
}

There are only 10 female deans within medical schools across the country, and women are vastly under-represented at the associate and senior associate dean levels (AAMC, 2003). 
The challenges of advancement and adequate representation for women within the leadership and senior ranks of academic health systems are in addition to the challenges faced by all psychologists in these settings. A recent survey conducted by the Research Office of the APA (2004b) in conjunction with the Association of Medical School Psychologists (AMSP) illustrates dilemmas faced specifically by women who are psychologists. Based on the responses of 1,304 psychologists employed in academic health centers, women hold $44 \%$ of the faculty positions available. Women are more likely than men to be employed by pediatric departments and less likely to be employed in independent psychology departments within medical settings. At the rank of full professor, women represent $24 \%$ of all positions, whereas at the rank of assistant professor, women occupy $61 \%$ of positions. Furthermore, advancement for women may not always result in equivalent tangible rewards. For instance, depending on rank, women make, on average, \$6,000-7,000 less in their base salaries and $\$ 9,000-23,000$ less in total income. Women who are full professors average $15 \%$ less than male full professors in total yearly income; women who are assistant professors average $11 \%$ less than men at similar rank.

The data suggest that when a female psychologist chooses a career in an academic health system, good mentoring may be vital to prepare her for the challenges associated with her gender and her professional discipline. She may also grapple with the reality that her work hours may be longer than her male counterparts while her salary may be less (APA, 2004b), and that professional advancement competes with personal commitment to forming a family (Mason \& Goulden, 2004).

Authors' Comments: Putting a Personal Face on the Issues

(C.K.). As a faculty member in the Department of Psychiatry at my university's medical school, I have been asked more than once by my main campus colleagues "How are you surviving?" The question was typically asked with a sympathetic look and a sigh that implied a woman would not choose to work in such a setting if she had the option of working in a main campus psychology department. This experience occurred primarily during my first several years on the faculty, and suggested my colleagues may have some realization of the career development challenges a woman and a psychologist confronts in a medical school setting. Yet, the opportunity to teach and con- duct scientific investigations in the lively clinical and interdisciplinary environment of a medical school was unquestionably a draw for me, as undoubtedly it is for many psychologists. The key is to facilitate the career development of individuals who make this choice.

(B.C.). Upon graduation I had several employment options, but a medical school seemed to be an ideal fit. I welcomed the diverse roles I would play as a teacher, researcher and clinician and the opportunity to impact large numbers of patients by impacting the behavioral education of physicians. Through my role as a faculty member with a joint appointment in the Department of Psychiatry and Behavioral Sciences and the Department of Family and Community Medicine, I have made a positive impact. I have succeeded in large part due to the good fortune of having wonderful mentors throughout my career who helped me chose and adapt to a career as a medical school psychologist. Ironically, all of my mentors are males and issues regarding gender have never been directly broached. However, at times, I have been cautioned that I should "soften" my more direct communication style since I am "a female."

\section{Primary Aims of Article}

Despite the continuing existence of career development challenges related to gender, there is no question that women can thrive within academic health systems. We argue, however, that effective mentorship and career development are facilitated by a full understanding of both potential gender issues and the culture of these systems. The primary aims of this article are threefold: (1) to discuss gender differences in social behaviors that may have implications for women in academic health systems; (2) to discuss the culture of these systems and how culture and gender interface; and (3) to provide guidelines for the effective mentorship and career development of women in these settings.

\section{A CONSIDERATION OF GENDER DIFFERENCES}

Despite the diversity evident among women and the similar distributions for men and women on most characteristics, meaningful gender differences do exist. The reasons for these differences are complex and may, in fact, primarily reflect societal expectations, social roles, and the cumulative impact of life 
experiences. Analyses of why these differences exist and why they are sometimes translated into disadvantages for women are beyond the focus of this article, but a full consideration of the issues facing women within academic health systems would be remiss to exclude the topic of differences. We have chosen to use an historical framework to provide context for this highly debated and politicized topic (Eagly, 1995, 1997).

Brief History of our Understanding of Gender Differences

In the opening section of her edited book, "Women, Men, and Gender," Walsh (1997) provides an overview of the history and changing focus of debates concerning gender differences. Perhaps not surprisingly, medical school settings played a key role in this history. Leading figures in the American Medical Association and medical education made a number of assertions concerning women that were prejudicial and without a firm scientific basis. Dr. Horatio Storer, vice president of the American Medical Association in 1866, characterized menstruation as "temporary insanity" and argued against female physicians because menstruation put them in a position of needing rather than providing medical aid (Storer, 1866; as reported in Walsh, 1997, p. 1). Dr. Edward Clarke, a former professor at Harvard Medical School, wrote a book titled, Sex and Education: Or, A Fair Chance for the Girls (1873), arguing that educating females as males was inconsistent with normal female development. In fact, he stated that the results were "monstrous brains and puny bodies; abnormally active cerebration and abnormally weak digestion; flowing thought and constipated bowels" (reported in Walsh, 1997; pp. 1-2). Walsh reports that this book was printed 17 times in 13 years.

By the late 1800s and consistent with psychology's growing emphasis on empirical research, several women scientists conducted studies that challenged these theories and beliefs. Survey studies demonstrated that menstruation was not a barrier to women's professional activities and that college life was associated with improvements in women's lives (reported in Walsh, 1997). Furthermore, the first experimental laboratory study on gender differences in mental abilities demonstrated the preponderance of gender similarities (Wooley, 1910). Despite such efforts, psychoanalytic theory, which conceptualized women in a passive, dependent, and subordinate role relative to men, became a dominant viewpoint in the field. This occurred despite Horney's arguments that psychoanalytic theories about women were fraught with male bias (Horney, 1926).

Comprising approximately one-third of the membership of the American Psychological Association (APA) by the 1930s, women still functioned almost entirely outside of academic circles where most research, theoretical work, and influential writing was taking place (Walsh, 1997). They were not able to obtain a stronger role within the profession until the social reform movements of the 1960s. The Association for Women in Psychology was formed in 1969 and Division 35, Psychology of Women, became an official division of the APA in 1973. Henceforth, we have witnessed dramatic increases in APA Task Forces, special interest sections within divisions, annual conference papers and symposia, and specialized journals devoted to women and gender. In fact, the APA recently prepared a report summarizing the original 52 demands made by women in the 1970s and the actions that the APA Council has taken on their behalf during the past 30 years (APA, 2004c).

In 1974, Eleanor Maccoby and Carol Jacklin published the well-known and highly influential book, Psychology of Sex Differences (1974), which synthesized some of the existing research on gender differences. As discussed by Eagly (1995), Maccoby and Jacklin's approach was relatively informal by today's standards. It involved summarizing studies, classifying them in terms of whether or not they obtained significant findings, and discussing overall trends. Although Maccoby and Jacklin noted some gender differences in types of intellectual abilities and aggression, they argued that, despite cultural stereotypes, there were few significant differences in most areas. Their book became a tool in arguments for gender equality. According to Eagly (1995), many feminist psychologists believed that null findings, or gender neutral findings of sameness, would increase women's chances for equal opportunity in society. Other psychologists, such as Carol Gilligan (1982), have emphasized what they report to be the special qualities of women. This relative emphasis on minimizing versus embracing gender differences has been controversial, particularly given the link-carefully pointed out by feminist psychologists-between the belief that women have a special aptitude for nurturance and relationships, and a restriction in women's activities to those involving nurturance and caregiving (Walsh, 1997). 
Gender Differences in Social Behaviors: Some Differences in Overlapping Distributions

Beginning in the late 1970s, meta-analytic techniques enabled sophisticated quantitative analyses of gender differences. In this discussion, we focus on consistent findings regarding social behaviors because these differences have the potential to influence career advancement. This is particularly true when women's social behaviors are not in synchrony with the priorities of leaders within the academic health system. The identified gender differences in social behavior are generally consistent with cultural stereotypes, although as Eagly and Tannen caution, gender stereotypes are exaggerations and so can lead others to perceive differences where none exist (Eagly, 1995; Tannen, 1990, p. 16). With that caution in mind, we believe nevertheless that some of the challenges faced by women in academic health systems develop at the interface between women's social behaviors and the culture of the health system, and arise because of a less than ideal fit between that culture and many women's modal behaviors.

Research has shown that women smile and laugh more in social settings (above average amounts of smiling in $65 \%$ of women and $35 \%$ of men (Hall, 1984). Similarly, studies indicate that women are better at sending and receiving messages nonverbally (e.g., Hall, 1978), approach others more closely (Stier \& Hall, 1984), agree more and act more friendly in group contexts (e.g., Anderson \& Blanchard, 1982; Cooper, 1979), have more nurturant tendencies, and are more likely to emerge as social facilitators in groups (e.g., Eagly \& Crowley, 1986; Eagly \& Johnson, 1990; Eagly \& Wood, 1991). Men, on the other hand, contribute behaviors more strictly oriented to accomplishing group tasks (Anderson \& Blanchard, 1982); are more dominant and controlling in task oriented groups; and are more likely to emerge as leaders in initially leaderless groups (Eagly \& Karau, 1991). Finally, it is well documented that men tend to be more aggressive than women (Eagly \& Steffen, 1986).

Highlighting the importance of individual and situational variables, a different picture of gender differences emerges when one considers only men and women in leadership roles within organizations (Eagly \& Johnson, 1990). Perhaps due to the selection criteria for managers and the forces that socialize them, stereotypic sex differences are less pronounced among organizational leaders (Eagly \& Johnson, 1990). In fact, such studies have revealed no gender differences in either task orientation (organizing activities to perform assigned tasks) or interpersonal style (maintenance of interpersonal relationships). A gender difference is still evident, however, in what is referred to as democratic versus autocratic orientation. In all types of leadership studies (experimental laboratory, assessment, organizational), women have been found to adopt a more democratic or participative style. This pattern of findings suggests that many leadership characteristics converge across genders as a result of organizational selection and self-selection. Advancement may require a strong task orientation coupled with excellent interpersonal skills. What continues to differ even in these settings, however, is women's tendency to use a more democratic and participative approach.

Taking a sociolinguistic approach, Robin Lakoff (1975) and Deborah Tannen (1997) have written extensively on gender and language. Lakoff discusses the different ways in which women have been taught to use language and the way in which language in general use refers to women. She argues that boys go through a developmental stage of "rough talk," during which they learn and are rewarded for stronger means of expression that serve them well in adulthood, whereas girls are consistently rewarded for types of linguistic expression that may not be as adaptive in the professional world (Lakoff, pp. 3-8). These include the use of tag questions that seek confirmation, the use of intonational patterns suggesting hesitancy, the use of compound requests rather than simple orders, and politeness that may seem to weaken the strength of a statement. Similarly, Tannen (1994) describes how women often tend to downplay their authority, seek approval, qualify their statements, and strive to reach consensus in situations where they are in the position of power or authority. She also cites examples of how directness in women may be seen as abrupt and somewhat tactless even though the same behavior in men is admired. Aware of the controversies surrounding the investigation of gender differences, Tannen comments:

\footnotetext{
In spite of these dangers, I am joining the growing dialogue on gender and language because the risk of ignoring differences is greater than the danger of naming them. Sweeping something big under the rug doesn't make it go away; it trips you up and sends you sprawling when you venture across the room. Denying real differences can only compound the confusion that is already widespread in this era of shifting and re-forming relationships between women and men. (p. 84)
} 
Tannen notes the old proverbs suggesting that women talk too much, and then reports study findings indicating that it is men who talk more at meetings, in group discussions, and in classrooms. Tannen provides many rich examples of possible gender differences in what she refers to as "rapport-talk" [that strengthens relationships] and "report-talk" [that focuses on factual matters] in private and public settings (Tannen, 1990; pp. 76-92). She also reviews the empirical findings of Eakins and Eakins (1978) who tape-recorded and studied university faculty meetings and found that men tended to speak more often and for longer periods of time. In fact, the men's turns ranged from 11 to 17 seconds; the women's turns ranged from 3 to 10 seconds. Similarly, analyses of recorded question-and-answer sessions at academic conferences indicated that the first comment or question was almost always from a man and that, on average, women's questions required less than half as much time as men's questions (means of $23.1 \mathrm{v}$. 52.7 seconds; Swacker, 1976; cited in Tannen, 1997) as men tended to make statements prior to their questions.

It is certainly reasonable to conjecture that men's more active or extended verbal participation raises their visibility in the academic health system and increases others' tendency to perceive them as high in knowledge, professional enthusiasm, and commitment. It is also possible that the tendency to use the more democratic approach often employed by females has certain disadvantages in such a system. For instance, a more agreeable and friendly approach, although appreciated and highly regarded in some respects, may not be the most advantageous overall in a competitive, hierarchical and fiscally constrained system.

\section{CULTURE OF ACADEMIC HEALTH SYSTEMS}

The mission of academic health systems generally includes educating the next generation of health care professionals, conducting programmatic research to advance knowledge, and providing patient care (e.g., University of Michigan, 2004). The translation of this mission into practice could occur within any of a number of cultural contexts, but the culture of most academic health systems in the United States seems to be largely defined by relatively rigid training and career advancement requirements; a male-dominated hierarchical structure; and a corporate model driven by economic pressures.
Rigid Training and Career Advancement Requirements

During the past century, university-based medical schools established higher standards for entry, lengthened the required training, and established faculties who devoted most of their efforts to the medical school (Rothstein, 1987; pp. 140-269). The goal has been to base clinical practice on research based knowledge. As research endeavors have become increasingly specialized, often requiring sophisticated technical training or laboratory setups, and as external funding for research has become essential, it takes more time to prepare for and launch research careers. At the same time, economic and market pressures have made it increasingly difficult for faculty to place equal emphases on research, clinical teaching, and clinical practice. When one considers the combination of prolonged training, the expectation that faculty devote most of their efforts to the medical school, and the required preparation and dedication for a successful research career, it is evident that the pathway to career advancement has become less flexible. A successful trajectory is best achieved via long-term training followed by full dedication.

As discussed by Hirshbein, Fitzgerald, and Riba (2004) this institutionalized track system, which is currently front-loaded with publishing and grant-writing demands, may result in women believing that they must choose between either research and career advancement, or family life. We are sensitive to the enormous diversity within groups of women in terms of these issues as well as the impact that such a tracked system has on men as well as women. Nevertheless, given the demands of childbearing and women's tendency to have greater involvement in early child rearing, such a system may disproportionately impact women. In these traditional systems, individuals who are on the instructional track or involved with research in addition to clinical teaching may be in the best position for promotions to leadership positions.

Male-Dominated Hierarchical Structure

The organizational structure of academic health systems is extremely hierarchical. Organizational charts generally begin with the university president or dean of the academic health system, then branch into associate deans, department chairs, division or section heads, program leads, and faculty. The flow of communication follows this organizational structure, and involvement in key meetings or on 
important committees may vary in accord with ones status in the organization.

Pat Heim, the well-known corporate motivational speaker and co-author of Hardball for Women (Heim \& Golant, 1992), argues that men are more likely to have been socialized to function easily within such hierarchies where the coach is the leader of a competitive group. Although girls now commonly participate on sports teams, Heim argues that girls and women place a greater focus on "fairness" rather than winning, on keeping power "dead even with colleagues," and on the process of conducting business. They may pay less attention to some of the symbols of power and hierarchy (i.e., office size, keys and access, chair height, parking convenience), even though these may be important to ones ability to function most effectively.

This male dominated structure is further underscored by the reality that women fill only a third of hospital executive positions and, on average, earn $16 \%$ less than their male counterparts (Abdel-Wahab, 2004). In her book, Women and Leadership in Healthcare (1999), Catherine Robinson-Walker argues that health care hierarchies benefit males more than females because of differences in personality between the genders. The author points to studies which show that within an employment setting, women engage in friendships based on sincerity whereas men form relationships for utilitarian purposes; men's comments are taken more seriously even if previously proposed by females; and women must work harder and longer and take less time off than men to succeed. The coupling of gender differences such as those highlighted by Robinson-Walker and those documented in the meta-analytic studies discussed previously suggest that males will continue to find it easier to climb the hierarchical ladder as the steps along the way are in better synchrony with more commonly masculine characteristics. This appears true even when females utilize masculine traits to advance their efforts as their gender alone increases the likelihood that their efforts and opinions may be ignored or minimized, and when they exert themselves in a masculine manner, they are more likely to be viewed negatively.

\section{Corporate Model Driven by Current Economic Pressures}

For centuries, the foundation of health care was based on physician autonomy and freedom of choice by patients (Vanderbilt Law Review, 1987). However, recent trends in the growing corporatiza- tion of medicine have transformed health care systems. Corporate models of medicine have raised concerns that the pressures created by competition for market share in medicine have created a Darwinian approach to survival (National Health Lawyers Association and the Academy of Health Care Attorneys, 1997).

This impact of corporatization is perhaps most evident in academic health systems where an era of substantial accountability in terms of finances and productivity is increasingly imposed (Hirshbein, Fitzgerald, \& Riba, 2004). These growing financial pressures have created a disadvantage for junior faculty as more emphasis is placed on clinical activities, which ultimately impede the research and teaching missions that are linked to promotion. This primary emphasis placed on an institution's revenue generation positions females at a further disadvantage because females tend to enjoy less advancement in academia (AAMC, 2003), find themselves more frequently in junior faculty-clinical track positions (Hirshbein, Fitzgerald, \& Riba, 2004), have a tendency to be more willing to be a team player (e.g., Eagly \& Crowley, 1986; Eagly \& Johnson, 1990; Eagly \& Wood, 1991), and receive less funding for research. For example, men received $\$ 8.6$ billion in extramural funding and women received $\$ 2$ billion in 1999 based on NIH statistics (Williams, 2000). This differential is largely, albeit not entirely, accounted for by the fact that women make up only $30 \%$ of medical school faculties, Thus, these findings further suggest that men will find it more feasible to advance in academia through traditional means such as a research path, whereas the corporate model of medicine has become another hurdle for women to leap to succeed in academic medicine.

\section{IMPLICATIONS FOR WOMEN'S CAREER ADVANCEMENT}

The career advancement of women in academic health systems can be facilitated and improved with (1) effective mentorship of individual women, and (2) a stronger systems' level emphasis on faculty diversity and the development of women faculty.

Individual Mentorship

Despite the American Medical Association's assertion that mentoring is one of the five elements required for success in medicine (AMA, 2002), its 
importance is often underestimated. We believe that this is even more true for women than for men. It is our treatise that for a female psychologist to excel, lack of good mentorship is a serious disadvantage in an academic health center where the leadership is predominantly male (e.g., Bickel et al., 2002), the culture is increasingly corporate (e.g., Bondurant, 1995; Souba, 2002), and the pathways to career advancement are somewhat limited.

We recommend that women in academic health settings prioritize the development of their careers through the advice and guidance of senior faculty. Although it is possible that women mentor other women more easily than men, what is most important in our view is the mentors' awareness and consideration of key gender and cultural issues. Multiple mentors are highly recommended due to the complexity of professional roles and duties filled by individual faculty members, and these mentors may cross professional domains. For example, in an academic health center, physicians are generally the largest faculty group. When female physicians mentor females of other disciplines such as psychology, and in turn, psychologists mentor female physicians, everyone's professional network is expanded.

Mentorship can serve many functions for women in faculty positions. One function extremely critical to academic careers is the facilitation of professional networking and the mentor's use of their own professional network to create academic opportunities for the mentee. Other functions include advice and consultation concerning decisions at career turning points; the management and prioritization of teaching, clinical, and research responsibilities; strategies for surviving and thriving within a hierarchical system; and individualized tutoring and feedback concerning academic activities.

Despite the potential benefits, many women in academic health systems do not have adequate mentorship and at times report negative mentoring relationships. For example, in 1999, the institution of the second author (BC), conducted a survey of students across all years of training prior to the establishment of a new mentoring program (Heyl, 2000) which asked specific questions regarding mentoring experiences, career plans, sociodemographics, and professional activities. A $28.9 \%$ response rate was achieved and the sample $(N=119)$ consisted of $46.2 \%$ males and $53.8 \%$ females. Only 40 respondents (33\% of the whole sample) reported having a mentor, and of those who were mentored, $45 \%$ were male and $55 \%$ were female. The survey results underscored the value of a mentoring relationship but also showed that there were striking gender differences regarding mentorship. While female mentors were more likely to provide psychosocial support to their mentees of either gender, male students reported that male (faculty) mentors had "selected" them as mentees. In contrast, when female students indicated that they had a mentor, the females described pursuing the relationship actively rather than being "chosen." In fact, not a single female in the survey indicated that a faculty member had initiated a mentoring relationship with them.

Bickel (2004) reports that, in similar surveys, female mentees are less likely to be encouraged to participate in outside professional activities, three times more likely to have mentors take credit for female mentees' work, and frequently perceive their mentors as negative role models. These findings are consistent with findings across health care professions despite the fact that women tend to benefit more than men from an effective mentoring relationship (RobinsonWalker, 1999). In order for effective mentoring to occur senior faculty must approach junior faculty with recognition that the mentee's needs may be vastly different than their own (Bickel, 2004).

Ironically, female faculty in positions of authority often find that their attempts to provide individual mentoring to others are ignored, or even thwarted. For example, although the number of female chairs within medical school settings is limited, studies show that female chairs find males as well as females under their leadership to be more resistant to reporting to them or accepting their leadership styles and decision making (Yedidia \& Bickel, 2001). Moreover, mentorship opportunities intended to help female faculty change or adapt to academic medicine are often under-utilized by females as women tend to be more willing to offer help to others then to ask for help for themselves (Richman, 2004).

\section{Group and Organization-Level Mentorship Strategies}

Experience shows that mentoring can be done through several venues and that formal and informal individual mentoring as well as group mentoring are essential. Women are in a unique position to take advantage of mentoring networks as they have a natural affinity for relationships. These networks can focus on providing opportunities for socialization, skills building, consultation, networking and brainstorming regarding multiple issues, including how to balance professional and personal demands. Without these 
networks, opportunities to crack "the glass ceiling" will be limited.

An example of a group model for mentoring is the Pathways to Leadership Conference offered through a joint effort of the Virginia based medical and professional schools (Hampton, Sanders, \& Klein, 2004). This conference began in 1993 and highlights renowned speakers including nationally known authors, medical school deans, and communication specialists (e.g., Drs. Pat Heim, Kathleen Brehony, Paula Stillman, Leonard Marcus). During this conference, programs are offered that focus on how to advance a career, understand organizational structures, handle confrontation, and set useful goals. The value of friendships is also emphasized.

A somewhat similar, albeit one-time event, was held at the medical school of one of the present authors (C.K.) in the early 1990s. Acknowledging that many of the strategies recommended for women in business and corporate settings apply within academic health systems, Pat Heim, co-author of Hardball for Women, was scheduled as the featured speaker for a daylong event focused on career development. Heim emphasized the importance of understanding work culture and breaking patterns of behavior that put one at a disadvantage in the business world (or academic health system world) of men. She noted that it was critical to learn the system's politics, the nature of workplace gamesmanship, and understand what it takes to be considered a team player and leader in the specific work culture.

Several of Pat Heim's recommendations or arguments have direct implications for the mentorship of women in academic health systems. One of her arguments is that women may need to learn to display their confidence and power, report their productivity to obtain credit for work completed, and learn not to qualify their statements concerning work that will be accomplished. That is, it is beneficial to simply state "I can do that" rather than to respond by pointing out barriers, or why it can't be done exactly as asked, or how complex it will be to work out given competing priorities and other pressing responsibilities. A second argument Heim makes is that women need to learn to engage in conflict and aggressive competition, and to realize that it is fine to be cordial and friendly after the competition. That is, they should not evaluate such changes in their own behavior as examples of loyalty or disloyalty; they must accept that it is possible to be friendly toward and work with people they don't particularly like. Finally, she notes the importance of knowing who is in charge and of respecting and demonstrating one's commitment to serve those in charge. She notes that it is important to indicate that one is a team player and that one understands the hierarchy.

The Association of Medical School Psychologists (AMSP) recently established the AMSP Consultation Program (2005) which includes a nationwide network of possible consultants and mentors (resource available at http://www.apa.org/divisions/div12/sections/ section8/index.htm). This was designed for psychologists at all levels of career development-from psychologists in training to senior faculty in major governance roles within academic health systems. It offers women as well as men the opportunity to link up with other psychologists who have expertise related to issues such as salary negotiation, involvement in professional organizations, establishment of a research network, and assistance with teaching materials. This type of organizational mentorship network can supplement the individual and group mentorship available at a faculty member's own institution.

\section{CHANGING THE SYSTEM}

Although women remain an underrepresented group in leadership positions in academia, systems' level leadership and mentoring can and should impact the academic environment in which women function. In McElvaine's Eve's Seed: Biology, the Sexes, and the Course of History (2001), the author cautions against the denial of biological traits that lead to gender differences. The author goes as far as stating: "What we need, above all else, is to achieve a genuine balance between feminine and masculine values" (p.376). This statement reminds the female psychologist in an academic health setting of the dangers associated with over-adjusting to the male-oriented environment and the need to work for increased valuation of feminine traits in the setting. The presence of gender differences does not imply that either men or women have inferior preparation, capability, or stamina for careers in any setting, including an academic health setting, nor does it suggest superiority of one gender or the other. Rather, the significance of such differences must be considered in terms of how they interface with the culture of the academic health system.

The AAMC report, Increasing Women's Leadership in Academic Medicine, included the recommendations that medical schools, teaching hospitals, and academic societies emphasize faculty diversity and the development of women faculty in 
department reviews, target the career development needs of women within the context of helping all faculty, and enhance the effectiveness of search committees in attracting women candidates (Bickel et al., 2002). One recommendation was particularly in line with the present discussion concerning the culture of academic health systems. The Committee recommended that medical schools, teaching hospitals, and academic societies "assess which institutional practices tend to favor men over women's professional development, such as defining 'academic success' as largely an independent act and rewarding unrestricted availability to work ... (p. 1)." This recommendation is consistent with the notion that more flexibility is needed in defining tracks or trajectories to success. It also has implications for how gender differences are evaluated and interpreted.

How academic health centers change to retain females may also define the future of medicine and psychology. With more and more females opting for private practices, academia is losing many of its most qualified and talented potential faculty within the pool of graduating clinicians. Borus (2004) argues that academic environments need to create opportunities for part time positions and fairer ways for sharing credit for work completed, regardless of whether the work addressed academic, clinical, or research responsibilities of the institution. Borus further suggests that institutions must consider altering timelines for advancement and creating mechanisms that work more effectively for providing time off for pregnancy and childrearing. These mechanisms should allow for the potential of re-entry to academic environments at midlife or provide additional resources for all females (e.g., child care, mentoring).

In concurrence with Borus we feel that mentoring networks have the potential to serve as catalysts for womens' career development within the academic health system. Such networks can provide a voice for gender equity while also acting on behalf of individual women. Such networks also have the potential to make recommendations to the leadership of academic health systems concerning optimal and perhaps diverse career paths for women. Similarly, mentoring networks could promote greater recognition of the strengths of women and the importance of assuring they receive good mentorship. And, perhaps as these networks expand, institutions can change to create family-friendly environments that promote cultural change and ultimately lead to the retention and advancement of well-deserving female faculty.

\section{SUMMARY}

Effective individual and group network mentorship strategies share the goal of creating the most favorable conditions possible for faculty, facilitating their growth and career development. The positive impact of these strategies can be enhanced by a systems' level emphasis on faculty diversity and the career development of women faculty. Furthermore, we argue that mentorship effectiveness will be maximized by an understanding of both gender issues and the culture of academic health systems-but caution is warranted. A focus on any one aspect of an individual (e.g., gender) can obscure the complexities of human behavior (Lott, 1997). Furthermore, patterns of gender variation in social behaviors and the characteristics of workplace cultures are both constantly evolving.

\section{REFERENCES}

Adel-Wahab, N. (2004). Women and leadership in healthcare [Review of the book Women and Leadership in Healthcare]. Journal of the American Medical Women's Association, 59, 77.

American Psychological Association. (2004a). Committee on Accreditation: 2003 Annual report. Washington, DC: Author. (Available from APA Office of Program Consultation and Accreditation, 750 First Street, NE, Washington, DC 20002).

American Psychological Association (2004b). 2003 Medical school/Academic medical center psychologists' employment survey. Washington, DC: Author. (Available from APA Office of Research, 750 First Street, NE, Washington, DC 20002).

American Psychological Association Committee on Women in Psychology. (2004c). 52 resolutions \& motions regarding the status of women in psychology: Chronicling 30 years of passion and progress. Washington, DC: Author. (Available from APA Women's Programs Office, 750 First Street, NE, Washington, DC 20002).

Anderson, L. R., \& Blanchard, P. N. (1982). Sex differences in task and social-emotional behavior. Basic and Applied Social Psychology, 3, 109-139.

Association of American Medical Colleges. (2003). Women in U.S. academic medicine statistics, 2002-2003. Washington, DC: Author.

Association of Medical School Psychologists. (2005). AMSP Consultation Program. Retrieved March 3, 2005, from http:// www.apa.org/divisions/div12/sections/section8/index.htm.

Bickel, J. (2004). Women in academic psychiatry. Academic Psychiatry, 28, 285-291.

Bickel, J., Wara, D., Atkinson, B. F., Cohen, L. W., Dunn, M., Hostler, S. et al. (2002). Increasing women's leadership in academic medicine: Report of the AAMC project implementation committee. Washington, DC, AAMC.

Bondurant, S. (1995). Health care reform continues: Themes for academic medicine. Academic Medicine, 70, 93-97.

Borus, J. E. (2004). Women and academic psychiatry (a commentary). Academic Psychiatry, 28, 278-281.

Cooper, H. (1979). Statistically combining independent studies: A meta-analysis of sex differences in conformity research. Journal of Personality and Social Psychology, 37, 131-146. 
Eagly, A. H. (1997). Comparing Women and Men: Methods, Findings, and Politics. In Walsh, M. R. (Eds.). Women, Men, \& Gender Ongoing Debates (pp. 24-31). New Haven, London: Yale University Press.

Eagley, A. H., \& Crowley, M. (1986). Gender and helping behavior: A meta-analytic review of the social psychological literature. Psychological Bulletin, 100, 283-308.

Eagly, A. H., \& Johnson, B. T. (1990). Gender and Leadership Style: A Meta-Analysis. Psychological Bulletin, 108, 233-256.

Eagly, A. H., \& Karau, S. J. (1991). Gender and the emergence of leaders: A Metal-Analysis. Journal of Personality and Social Psychology, 60, 685-710.

Eagly, A. H., \& Steffen, V. J. (1986). Gender and aggressive behavior: A meta-analytic review of the social psychological literature. Psychological Bulletin, 100, 309-330.

Eagly, A. H., \& Wood, W. (1991). Explaining Sex Difference in Social Behavior: A Metal-Analytic Perspective. Personality and Social Psychology Bulletin, 17, 306-315.

Eagly, A. H. (1995). The Science and Politics of Comparing Women and Men. American Psychologist, 50(3), 145-158.

Eakins, B. W., \& Eakins, A. G. (1978). Sex Differences in Communication. Boston: Houghton Mifflin.

Gilligan, C. (1982). In a Different Voice: Psychological theory and women's development. Cambridge, Mass.: Harvard University Press.

Hall, J. A. (1978). Gender effects in decoding nonverbal cues. Psychological Bulletin, 85, 845-857.

Hall, J. A. (1984). Nonverbal sex differences: Communication accuracy and expressive style. Baltimore: Johns Hopkins University Press.

Hampton, C. L., Sanders, K. M., \& Klein, W. S. (2004). Pathways to leadership conference: A professional development resource for women in medicine. Journal of the American Medical Women's Association, 59, 82-83.

Heim, P., \& Golant, S. K. (1992). Hardball for women: Winning at the game of business. New York: Plume.

Heyl, A. (2000, October). Facilitated mentoring: Means for promoting lifetime learning. Presented at the 111th AAMC Annual Meeting, Chicago, IL.

Hirshbein, L. D., Fitzgerald, K., \& Riba, M. (2004). Women and teaching in academic psychiatry. Academic Psychiatry, 28, 292298.

Horney, K. (1926). The flight from womanhood. In Kelman, H. (Ed.), Feminine psychology (pp. 54-70). New York: Norton, 1967.

Lakoff, R. (1975). Language and Women's Place. New York: Harper Colophon Books.

Lott, B. (1997). Cataloging Gender Differences: Science or Politics? In Walsh, M. R.(Eds.), Women, men, \& gender ongoing debates (pp. 19-23). New Haven, London: Yale University Press.

Maccoby, E. E., \& Jacklin, C. N. (1974). The Psychology of Sex Differences. Stanford, CA: Stanford University Press.

Mason, M. A., \& Goulden, M. (2004). Do babies matter (Part II): Closing the baby gap. Academe, 90, 11-17.
McElvaine, R. S. (2001). Eve's seed: Biology, the sexes and the course of history. New York: NY: McGraw Hill.

National Health Lawyers Association and the Academy of Health Care Attorneys. (1997). Patient care and professional responsibility. Impact of the corporate practice of medicine doctrine and related laws and regulations. Washington, DC.: Author.

Nonnemaker, L. (2000). Women physicians in academic medicine: new insights from cohort studies. New England Journal of Medicine, 342, 399-405.

Richman, R. C. (2004). Networking lessons for women professionals-Connecting the dots, building matrices. Journal of the American Medical Women's Association, 59, 7-9.

Robinson-Walker, C. (1999). Women and Leadership in Healthcare. San Francisco, CA: Jossey-Bass.

Rothstein, W. G. (1987). American Medical Schools and the Practice of Medicine. New York: Oxford University Press.

Souba, W. W. (2002). Academic medicine and the search for meaning and purpose. Academic Medicine, 77, 139-144.

Stier, D. S., \& Hall, J. A. (1984). Gender differences in touch: An empirical and theoretical review. Journal of Personality and Social Psychology, 47, 440-459.

Swacker, M. (1976). Women's verbal behavior at learned and professional conferences. In Dubois, B. L., \& Crouch, I. (Eds.), The sociology of the languages of American women (pp. 155-160). San Antonio: Trinity University.

Tannen, D. (1997). Women and Men Talking: An International Sociolinguistic Approach. In Walsh, M. R. (Eds.), Women, men, \& gender ongoing debates (pp. 82-90). New Haven, London: Yale University Press.

Tannen, D. (1990). You Just Don't Understand: Women and Men in Conversation. New York: William Morrow and Company, Inc.

Tannen, D. (1994). Talking from 9 to 5: How Women's and Men's Conversation Style Affect Who Gets Heard, Who Gets Credit, and What Gets Done at Work. New York: William Morrow and Company, Inc.

University of Michigan. University of Michigan Hospitals and Health Centers Mission, Vision and Values. Retrieved November 30, 2004, from http://www.med.umich.edu/exec/ mission.htm.

Vanderbilt Law Review. (1987, March). The corporate practice of medicine doctrine: An anachronism in the modern health care industry (40, No. 2). Author.

Yedidia, M. J., \& Bickel, J. (2001). Why aren't there more women leaders in academic medicine? The views of clinical department chairs. Academic Medicine, 76, 453-465.

Walsh, M. R. (Ed.). (1997). Women, Men, \& Gender Ongoing Debates. New Haven, London: Yale University Press.

Williams, P. (2000, Winter). Men receive larger NIH research grants-Why? Women in Medicine Network, Eastern Virginia Medical School, $2,4$.

Wooley, H. T. (1910). Psychological literature: A review of the recent literature on the psychology of sex. Psychological Bulletin, $7,335-342$. 